\title{
Effect of Proprioceptive Exercise Training on Joint Reposition Sense and Balance of Athletes with Knee Injury
}

\section{Gajanana Prabhu, B.}

Assistant Professor, Department of P. G. Studies and Research in Physical Education, Kuvempu University, Shimoga 577451 Karnataka,

Phone: 09845311458; email prabhuji888@gmail.com

\begin{abstract}
The purpose of the study was to find the effects of proprioceptive exercise training on joint reposition sense and balance in athletes with knee joint injury. The subjects selected for the purpose of the study were five male post graduate students between the age group of 23 to 29 years pursuing their M. P. Ed. during the academic year 2012-13. The subjects suffered from knee injury during sporting endeavors at intercollegiate and inter University levels. All the subjects were recovering from sprained ligament of right leg that occurred within a span of one year. Tests included were Weight-Bearing Joint Reposition Sense; Non-Weight-Bearing Joint Reposition Sense; Romberg's test- Bilateral; and Romberg's test- Unilateral. The experimental design selected for the present investigation was single group pre test- post test design. The selected tests were administered to the subjects twice during pre test and post test situations. Mean, Standard Deviation ' $t$ ' tests were included to statistically treat the data. The pre and post test scores of subjects on joint reposition sense test with and without weight bearing, and bilateral Romberg's test for balance showed significant differences. The unilateral Romberg's test for balance does not show significant difference. It was concluded that the proprioceptive exercise training during post injury rehabilitation has beneficial effects on joint position sense and balance of athletes with knee injury.
\end{abstract}

KEY WORDS: Knee injury, Sprain, Rehabilitation, Proprioceptors, Proprioceptive exercises.

\section{Introduction}

Many injuries are season-ending or even career- ending. In these cases it is particularly important to be realistic with the athlete in setting the goals for recovery and return. Determining when to allow an athlete to resume training and competition following an injury is one of the most crucial and difficult functions of any physical education personnel. A thorough understanding of the mechanics, physiology, patho-anatomy, and healing principles in injured tissues is essential to making appropriate decisions regarding return to play.

One of the major contributions the trainer can make to the welfare of the athlete is in the area of rehabilitation. The overall goal of the treatment and rehabilitation programme is to return the athlete to his or her desired level of participation as soon and as safely as possible. The type of rehabilitation program that is prescribed frequently determines what level of athletic participation will be possible in the future. Rehabilitation restores full flexibility, 
strength, endurance and motion to an injured athlete.

Returning the injured athlete to competition usually involves a step-wise progression through a rehabilitative process, with the end goal being resumption of participation at the pre injury level of play. It is also important to prevent further injury by allowing adequate healing and providing appropriate exercise during recovery.

As the injury resolves, specific attention must be paid to strengthening both the injured tissues and the associated dynamic supporting structures. Often tissues that are not involved in the initial injury will be weakened through immobilization or reflex inhibition. Functional rehabilitation is aimed at neuromuscular retraining, strengthening of injured and associated supporting tissues, and restoration of normal joint motion. This stage of treatment is primarily accomplished through self-directed exercise with supervision from the trainer and therapist.

Exercise is a vital part of rehabilitation process for most of the sports related injuries. As popularly believed the athlete cannot resume training once his course of treatment is completed. Returning to pre-injury state is most essential to avoid recurrent injury and ensure high sports performance. Once the pain has subsided athlete's flexibility and strengthening goals have to be achieved through systematic training.

Following injury to joints and ligaments the receptors are also damaged, which means the information that is usually sent to the brain is impaired. As a consequence the joint feels odd or just doesn't feel right. The loss of position sense puts the joint at further risk of injury because of the loss of stability, postural control and functional capacity. The therapeutic values of exercise come into effect at this stage of rehabilitation during injury to muscle, tendon or ligament. The rehabilitation programme should essentially include proprioceptive training.

Proprioception is the body's ability to transmit a sense of position, analyze that information and react (consciously or unconsciously) to the stimulation with the proper movement (Houglum, 2001). Proprioception includes balance, coordination and agility because the body's proprioceptors control all these factors. It describes the body's ability to react appropriately to external forces.

No single receptor provides all the information needed by the central nervous system to evaluate posture and body position. Input from muscle and joint receptors, vestibular apparatus, and the eyes are synthesized for total body position information (Stone et. al., 1994). Proprioceptive feedback reaches the central nervous system from receptors located in muscles and joints, vestibular apparatus in the inner ear, and the eyes. Muscle and joint receptors are stimulated by movements of the musculoskeletal system. The vestibular apparatus provides information on whole body position and is stimulated when upright body posture changes. The eyes help orient the head and body with respect to the environment. Since athletes must attend to sport-related stimuli when performing, they rely on information from muscle and joint receptors and the vestibular apparatus to 
balance and maintain body position. When visual stimuli are removed or are distracting, damaged muscle and joint receptors are reeducated to provide accurate positional information to the central nervous system.

\section{Raibeiro and Oliveira (2012)} indicate that joint position sense and muscle function is still impaired after an accelerated rehabilitation protocol for anterior cruciate ligament reconstruction surgery suggesting that these individuals are still predisposed to further muscle or proprioceptive related knee injury. Exercise is an imperative part of the rehabilitation process for most sports injuries. Attaining pre-injury flexibility and strength is invariably an essential part of rehabilitation. Rehabilitation programme must essentially include proprioceptive training due to the impairment of such capabilities.

A number of studies have shown that proprioception training can reduce the risk of injuries in sports, but the mechanism is still not clearly understood. Proprioceptive exercise could be a better choice of treatment from physiotherapy point of view in the management of osteoarthritis of knee (Mondam \& Prakash, 2012). The results of the study by Panics et al (2013) show that the proprioception training improves the joint position sense in elite female handball players. This may explain the effect of neuromuscular training in reducing the injury rate.

The present study focuses on the importance of exercise for proprioception in the perspective of post injury rehabilitation in sports. Injuries to a joint, specifically ligament sprains, have the potential to diminish proprioception and subsequently result in recurrent injury. Proprioceptive exercises provides training to brain, nerves and muscles to communicate better to correctly identify where the body is and how it is moving. The purpose of the study was to find the effects of proprioceptive exercise training on joint reposition sense and balance in athletes with knee joint injury.

\section{Materials \& Methods}

Selection of subjects: The subjects selected for the purpose of the study were five male post graduate students pursuing their M. P. Ed. during the academic year 2012-13. The subjects selected were sufferers of knee injury during sporting endeavors at intercollegiate and inter University levels. All the subjects were recovering from injury that occurred within a span of one year and their age ranged between 23 to 29 years. The scanning reports of the subjects revealed the fact that all the subjects were afflicted with sprained ligament of right leg.

Selection of test items: The present study included testing of joint position sense and balance of subjects during pre and post test situations. All together four tests were conducted in order to assess joint position sense and balance of subjects. These were:

- Test 1: Weight-Bearing Joint Reposition Sense (Drouin et al, 2003)

The weight-bearing condition measured participants' ability to actively reproduce a target angle of $30^{\circ}$ using 
methods previously described.' While in single-leg stance on a 6-in-high box, each subject was instructed to slowly squat. The researcher instructed the subject to stop and pause for 15 seconds when the knee-joint angle measured $30^{\circ}$. Next, the subject returned to a standing position and waited for 15 seconds. The subject was then instructed to reproduce the target angle for that trial as accurately as possible. Each subject maintained balance by leaning backward against the wall. The non testing leg remained fully extended and non-weight-bearing off the edge of the box during the entire test. Between trials, each subject walked $20 \mathrm{ft}$ to eliminate any proprioceptive memory of the test.

- Test 2: Non-Weight-Bearing Joint Reposition Sense (Drouin et al, 2003)

To assess JRS in the non-weightbearing condition, each subject was seated on a chair reclined to $55^{\circ}$. The joint line of the dominant leg was aligned $10 \mathrm{~cm}$ from the edge of the seat. While seated with the test leg fully extended, the subject was instructed to slowly flex the knee. The researcher instructed the participant to stop when the knee-joint angle measured $30^{\circ}$ and to hold the position for 15 seconds. The subject then returned the test leg to the fully extended position and paused for 15 seconds. Next, the subject was instructed to reproduce the target angle of that trial as accurately as possible. Between trials the subject performed 5 repetitions of knee flexion and extension to eliminate any proprioceptive memory.

- Test 3: Romberg's testBilateral (wikipedia.org)
It is a test used by clinicians in a neurological examination and used to investigate the cause of loss of motor coordination. The examination is based on the premise that a person requires at least two of the three following senses to maintain balanced while standing: Proprioception (the ability to know one's body in space); Vestibular function (the ability to know one's head position in space); and Vision (which can be used to monitor [and adjust for] changes in body position). The subject was asked to stand erect with feet together and eyes closed. The investigator stood close by as a precaution in order to stop the subject from falling over and hurting himself. The movement of the body was watched in relation to a perpendicular object behind the subject (corner of the room). A positive sign was noted when a swaying, sometimes irregular swaying and even toppling over occurred. The essential feature is that the subject becomes more unsteady with eyes closed.

The essential features of the test are as follows:

- The subject stands with feet together, eyes open and hands by the sides.

- The subject closes the eyes while the examiner observes for a full minute.

Because the examiner is trying to elicit whether the patient falls when the eyes are closed, it is advisable to stand ready to catch the falling patient. Romberg's test is positive if the patient sways or falls while the patient's eyes are closed.

- Test 4: Romberg's test- Unilateral (Sekir \& Gur, 2005) 
During 'eyes open' balance tests, subjects looked straight ahead at a cross marked at approximately eye level on the wall 2-m away. For unilateral Romberg test, subjects stood on the test side limb with their stance foot centered on the floor and with their knee in slight flexion. They were instructed to lift the limb that was not being tested by bending the knee, and holding it at approximately $90^{\circ}$ of knee flexion. Once the subjects were in this position, and stated that they were ready, data collection was initiated. For each test balance measurements were performed for a maximum 30 seconds (provided subjects did not move their body or make contact with the ground). Subjects were asked to stand unsupported with their arms at their side. The subjects performed this test without shoes and socks to negate any extraneous skin sensation from clothing touching the foot area. The outcome measure (time in seconds) used for the balance assessment was averaged over the 2 trials, for each test situation.

The experimental design: The experimental design selected for the present investigation was single group pre test- post test design. This design exhibits minimal control. There is somewhat more structure, there is a single selected group under observation, with a careful measurement being done before applying the experimental treatment and then measuring after. The selected tests were administered to the subjects twice during pre test and post test situations.

The treatment: Treatment was given to all the subjects by a planned model of proprioceptive exercises prepared with the help of experts and reviews gone through. The treatment in the form of cost effective and simple exercises done on the floor as well as on the balance (wobble) board was accomplished three times a week up to eight weeks duration. List of exercises is provided in table 1 .

Statistical techniques: In order to make inferences on the effectiveness of treatment given for eight weeks various statistical techniques were employed. The raw data on pre test and post test was subjected to descriptive statistics line mean and standard deviation. Further, in order to compare mean scores of various tests on pre and post tests- ' $t$ ' test was employed.

Table 1: Description of proprioceptive exercises

\begin{tabular}{|c|c|}
\hline $\begin{array}{l}\text { Walk forward through } 6 \\
\text { boxes (50cm x } 50 \mathrm{~cm} \text { ) on one- } \\
\text { foot (in-in-out to right-in-in- } \\
\text { out to left). } \\
\text { Walk heel-to-toe along a } 3 \mathrm{~m} \\
\text { line marked on a medium- } \\
\text { density polyfoam mat. } \\
\text { Stand on one leg with knee } \\
\text { straight- raise leg forward \& } \\
\text { backward. } \\
\text { Stair case climbing- } 3 \text { steps } \\
\text { Stand with feet } \\
\text { approximately shoulder width } \\
\text { apart and extend arms out } \\
\text { slightly forward and lower } \\
\text { than the shoulder. Lift both } \\
\text { heels off the floor and try to } \\
\text { hold the position for } 10 \\
\text { seconds. Followed by } \\
\text { climbing a regular } 3 \text { steps } \\
\text { staircase ( } 17 \text { cm high and } 23 \\
\text { cm wide), -up and -down. } \\
\text { Toe walking } \\
\text { Heel walking } \\
\text { Forward leg swings } \\
\text { Side ward leg swings } \\
\text { One leg heel raise } \\
\text { One leg squat }\end{array}$ & $\begin{array}{l}\text { Advanced one leg balance for } \\
\text { 30 seconds } \\
\text { Maximum forward backward } \\
\text { leg swings with knee extended } \\
\text { Bicycle leg swings without } \\
\text { resistance } \\
\text { Double leg balance on a } \\
\text { wobble board Two leg } \\
\text { Balance board exercises (with } \\
\text { big balls as distracters) } \\
\text { One leg Balance board } \\
\text { exercises (with big balls as } \\
\text { distracters) } \\
\text { Two leg Balance board } \\
\text { exercises (with slightly } \\
\text { smaller balls as distracters) } \\
\text { One leg Balance board } \\
\text { exercises (with slightly } \\
\text { smaller balls as distracters) } \\
\text { Two leg Balance board } \\
\text { exercises (with smaller balls } \\
\text { as distracters) } \\
\text { One leg Balance board } \\
\text { exercises (with smaller balls } \\
\text { as distracters) } \\
\text { Two leg Balance board } \\
\text { exercises (with talking as } \\
\text { distraction) } \\
\text { One leg Balance board } \\
\text { exercises (with talking as } \\
\text { distraction) }\end{array}$ \\
\hline
\end{tabular}

\section{Results \& Discussion}

The raw data on joint reposition sense test with and without weight bearing, unilateral and bilateral Romberg's test 
during pre and post test were subjected to statistical treatment. The mean and standard deviation of tests are provided in table 2 .

Table 2: Details on descriptive statistics of subjects on joint reposition and balance tests

\begin{tabular}{clcc}
\hline $\begin{array}{c}\text { Sl. } \\
\text { No }\end{array}$ & \multicolumn{1}{c}{ Tests } & Pre test & Post test \\
\hline & $\begin{array}{l}\text { Joint reposition } \\
\text { sense test- with } \\
\text { weight bearing (in } \\
\text { angles) }\end{array}$ & $72 \pm 11.22$ & $39.8 \pm 2.49$ \\
2 & $\begin{array}{l}\text { Joint reposition } \\
\text { sense test- without }\end{array}$ & $34 \pm 5.15$ & $\mathbf{2 4 . 6 \pm 1 . 9 5}$ \\
\hline
\end{tabular}

\begin{tabular}{|c|c|c|c|}
\hline & $\begin{array}{l}\text { weight bearing (in } \\
\text { angles) }\end{array}$ & & \\
\hline 3 & $\begin{array}{l}\text { Bilateral Romberg's } \\
\text { test (in seconds) }\end{array}$ & $\begin{array}{c}34.4 \pm 16.5 \\
6\end{array}$ & $\begin{array}{c}47.8 \pm 13.7 \\
0\end{array}$ \\
\hline 4 & $\begin{array}{l}\text { Unilateral } \\
\text { Romberg's test (in } \\
\text { seconds) }\end{array}$ & $21.6 \pm 5.59$ & $27.2 \pm 3.03$ \\
\hline
\end{tabular}

Table 2 depicts mean and standard deviation of joint reposition and balance scores. In order to find out the differences in mean scores and make inferences, the data was further treated with ' $t$ ' test. Details are given in the following table 3.

Table 3: t-test results

\begin{tabular}{|c|c|c|c|c|c|c|c|c|}
\hline & \multicolumn{5}{|c|}{ Paired Differences } & \multirow{3}{*}{$\mathbf{t}$} & \multirow{3}{*}{ df } & \multirow{3}{*}{ Sig. (2-tailed) } \\
\hline & \multirow[t]{2}{*}{ Mean } & \multirow{2}{*}{$\begin{array}{c}\text { Std. } \\
\text { Deviation }\end{array}$} & \multirow{2}{*}{$\begin{array}{l}\text { Std. Error } \\
\text { Mean }\end{array}$} & \multicolumn{2}{|c|}{$\begin{array}{l}\text { 95\% Confidence } \\
\text { Interval of the } \\
\text { Difference }\end{array}$} & & & \\
\hline & & & & Lower & Upper & & & \\
\hline $\begin{array}{c}\text { Pre }- \text { Post test } \\
\text { comparison of joint } \\
\text { reposition sense test with } \\
\text { weight bearing }\end{array}$ & 32.20 & 8.928 & 3.993 & 21.115 & 43.285 & 8.065 & 4 & 0.001 \\
\hline $\begin{array}{l}\text { Pre - Post test } \\
\text { comparison of joint } \\
\text { reposition sense test } \\
\text { without weight bearing }\end{array}$ & 9.40 & 4.879 & 2.182 & 3.343 & 15.458 & 4.308 & 4 & 0.013 \\
\hline $\begin{array}{l}\text { Pre - Post test results of } \\
\text { bilateral Romberg's test } \\
\text { for balance }\end{array}$ & 13.40 & 5.941 & 2.657 & 20.777 & 6.023 & 5.043 & 4 & 0.007 \\
\hline $\begin{array}{l}\text { Pre - Post test results of } \\
\text { unilateral Romberg's test } \\
\text { for balance }\end{array}$ & 5.60 & 7.635 & 3.415 & 15.081 & 3.881 & 1.640 & 4 & 0.176 \\
\hline
\end{tabular}

Table 3 makes it very clear that the pre and post test scores of subjects on joint reposition sense test with and without weight bearing, and bilateral Romberg's test for balance shows significant difference. The obtained ' $\mathrm{t}$ ' ratio is 8.065 , 4.308 and 5.043 respectively, which is higher than the tabulated ' $t$ ' value (2.776) required for significant difference. Hence null hypothesis is rejected and it is affirmed that there is significant improvement in these aspects during post treatment testing.

Further, Table 3 makes it apparent that the pre and post test scores of subjects on unilateral Romberg's test for balance do not show significant difference. The obtained ' $\mathrm{t}$ ' ratio is 1.640 which is lower than the tabulated ' $t$ ' value (2.776) required for significant difference.

On the basis of reviews gone through it was understood that the role of proprioceptive exercise training in knee injured athlete was poorly researched topic. An improvement in joint reposition sense with and without weight bearing; as well as bilateral and unilateral balance was expected through proprioceptive exercise training.

Joint reposition sense with weight bearing: Under the limitations of the study, significant improvement was 
observed in joint reposition sense with weight bearing in sports persons with knee injury. The proprioceptive exercise training model selected in the present study can be useful in obtaining joint reposition sense with weight bearing in knee injured sportspersons.

The findings of the study conducted on the effects of a multi-station proprioceptive exercise program on functional capacity, perceived knee pain, and sensoriomotor function.by Sekir \& Gur (2005) suggests that using a pure proprioceptive/balance exercise program it is possible to improve functional capacity, postural control and decrease perceived knee pain in patients with bilateral knee osteoarthrosis.

Joint reposition sense without weight bearing: Under the limitations of the study, significant improvement was observed in joint reposition sense without weight bearing in sports persons with knee injury. The proprioceptive exercise training model selected in the present study is also useful in obtaining joint reposition sense without weight bearing in knee injured sportspersons.

Knee joint position sense was assessed by active tests with active limb matching responses in supine lying and in unilateral weight bearing stance using repositioning of the whole limb whilst focusing on the knee, and in supine lying using repositioning confined to the knee. Active knee joint position sense assessments in unilateral weight bearing stance with eyes closed and hand support produced more accurate and reliable results than non weight bearing assessments in supine lying. Active non weight bearing knee joint position sense assessments involving knee repositioning were more reliable, but not more accurate than the non weight bearing assessments with limb repositioning (Stillman \& $M c$ Meeken, 2001).

Bilateral balance: Bilateral balance measured in terms of Romberg's balance test showed significant improvement in sports persons with knee injury in the present investigation.

Demirhan et al, (2005) investigated short-term clinical effects of kinesthesia and balance exercises in patients with knee osteoarthritis. Additive positive effects of kinesthesia and balance exercises in knee osteoarthritis have been demonstrated. Used in clinical applications, they should be able to increase the functional capacities of patients.

Maggo et al (2011) compared the effectiveness of proprioceptive exercises and strengthening exercises in treatment of osteoarthritis of knee in terms of pain and functional disability. The study between three groups comparing conventional treatment to strengthening and proprioceptive exercises suggest that combination of the two brings better relief to the subjects of knee OA in reducing pain and functional disability.

Unilateral balance: Unilateral balance measured in terms of Romberg's balance test did not show significant improvement in sports persons with knee injury in the present investigation. The reasons can be attributed to insufficient duration of 
treatment or the selection of exercises in the present context.

Conclusion: Proprioceptive exercise training during post injury rehabilitation has beneficial effects on joint position sense and balance of athletes with knee injury. Favorable effects of proprioceptive exercises have to be clearly understood by coaches, trainers and physicians in avoiding recurrent injury to knee. It must become an imperative part of any rehabilitative program aiming at regaining functional performance of knee. This will aid in return of the athlete with pre injury state of knee functioning and self confidence.

\section{References}

Houglum, P.A. 2001. Therapeutic Exercise for Athletic Injuries. Champaign, IL: Human Kinetics.

Stone, J A., Partin N. B., Lueken J. S., Timm K. E. and Ryan E. J. 1994. Upper Extremity Proprioceptive Training. Journal of Athletic Training, 29(1): 15-18.

Silva, F., Ribeiro, F., Oliveira, J. 2012. Effect of an accelerated acl rehabilitation protocol on knee proprioception and muscle strength after anterior cruciate ligament reconstruction. April. AvailableURL from: http://ciafel.fade.up.pt/aehd/index.php/aehd/ article/view/113

Mondam, S., Babu V. S., R. Kumar B, Prakash. J. 2012. A comparative study of proprioceptive exercises versus conventional training program on osteoarthritis of knee. Available from

URL http://www.isca.in/rjrs/archive/v1i12/6.ISCA -RJRS-2012-352.pdf
Panics, G., Tallay A., Pavlik, A., Berkes, I. 2008. Effect of proprioception training on knee joint position sense in female team handball players. April. Available from URL http://www.mendeley.com/catalog/effectproprioception-training-knee-joint-positionsense-female-team-handball-players/

Drouin, J.M., Houglum, P.A., Perrin, D.H., Gansneder, B.M. 2003. Weight bearing and non- weight-bearing knee joint reposition sense are not related to functional performance. Journal of Sport Rehabilitation, 12: 54-66. April. Available from URL http://en.wikipedia.org/wiki/Romberg\%27s_ test

Sekir, Ufuk. and Gur, Hakan. 2000. A multistation proprioceptive exercise program in patients with bilateral knee osteoarthrosis: functional capacity, pain and sensoriomotor function. a randomized controlled trial. Journal of Sports Science and Medicine. 4: 590-603.

Stillman, Barry, C. and McMeeken, Joan, M. 2001. The role of weight bearing in the clinical assessment of knee joint position sense. Australian Journal of Physiotherapy. 47: 247-253.

Demirhan., D., Aydin, Resa., Baskent, Akin., and Celik, Ajda. 2005. Effects of Kinesthesia and Balance Exercises in Knee Osteoarthritis. Journal of Clinical Rheumatology, 11(6): 303-310.

Maggo, A., Shobhit, Saxena., Shalini, Grover. 2011. The Effect of Proprioceptive Exercises and Strengthening Exercises in Knee Osteoarthritis. Indian Journal of Physiotherapy and Occupational Therapy. 5(3): 144-148.

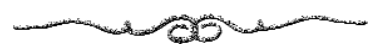

